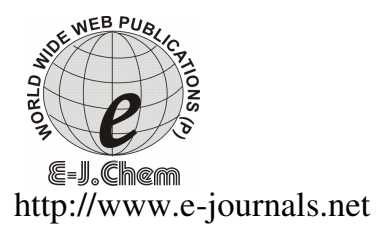

ISSN: 0973-4945; CODEN ECJHAO

E-Journal of Chemistry

Vol. 4, No.1, pp 137-144, January 2007

\title{
A Study of Substituted Aliphatic Sulphides on the Corrosion Behaviour of Zinc in Ammonium Chloride Solution
}

\author{
R.VENCKATESH*, P.S.SYED SHABUDEEN and S.GOPAL
}

\author{
Advanced Materials Research Laboratory \\ Kumaraguru College of Technology \\ Coimbatore- 641 006, Tamilnadu, India
}

Received 7 September 2006; Revised 16 October 2006, 1 November 2006

\begin{abstract}
Sulphur containing organic compounds decreases the corrosion rate by increasing the hydrogen over potential on zinc metal due to their electron donating groups. Their inhibiting effect was found to be associated with their adsorption on the active centers of the metal. The inhibition efficiencies of some aliphatic sulphides in ammonium chloride solution have been studied by weight loss studies, polarization and impedance measurements. The effect of substituent groups is correlated with their inhibition performance. These studies due to their relevance in $\mathrm{Zn}$ Manganese dry batteries assume their importance.
\end{abstract}

Keywords : Aliphatic sulphide inhibitors, Zn - Manganese dry batteries, Impedance Measurement, Polarization Study

\section{Introduction}

In long history of zinc-manganese battery production soluble mercury salt is almost exclusively used as zinc corrosion inhibitor because the amalgamation of zinc surface through chemical displacement is effective in suppressing zinc corrosion during cell storage and not hindering zinc dissolution during cell discharge. However mercury and its soluble salts are harmful pollutants being highly toxic. Increasing awareness of the importance of environmental protection has called for alternative inhibitors for zinc corrosion. It is known that in acidic or nearly neutral solutions certain nitrogen or sulphur containing organic compounds exhibit good inhibition of zinc corrosion ${ }^{1-4}$. Rudresh and Mayanna ${ }^{1}$ studied the effect of aliphatic amines on the corrosion behavior of zinc in acidic solution. Li et. al., 
studied the effect of some of the tetraammonium salts for zinc ${ }^{5}$. Gonzalez et.al have studied the corrosion resistance of galvanished steel by some polyamides ${ }^{6}$. Bhejiwala and Vashi studied aniline and hexamine is used as inhibitors for zinc and their effect is studied. They may act as precipitators, passivators vapour phase cathodic and anodic inhibitors. The mechanism of action of such inhibitors has been studied ${ }^{7,8}$. Gad Allah et. al., ${ }^{9}$ studied the effects of several pyrazole derivatives on the corrosion rate of zinc in $\mathrm{HCl}$ solutions. All the substances studied show some inhibiting effect. The differences between the inhibiting effects of these pyrazoles were discussed from the view point of the electronic properties of their substituent groups.

Maja et. al., ${ }^{10}$ studied the inhibiting effects of various types of organic compounds including aliphatic amines on zinc corrosion in $\mathrm{NH}_{4} \mathrm{Cl}$ solution which influence the anodic and cathodic polarization behavior of zinc. In the present study the effect of substituted aliphatic sulphides like ethylbutyl sulphide, [EBS], dibutyl sulphide [DBS] and Allylmethyl sulphide [AMS] on corrosion of zinc in $26 \%$ ammonium chloride medium is studied.

\section{Experimental}

The chemicals used were of AR grade. The solutions were prepared using double distilled water. Zinc (99.99\%) was mechanically polished on 4/0 emery paper. The surface was electropolished in ethanol-phosphoric acid prior to each experiment.

\section{Immersion test}

This provides a direct measure for evaluating the corrosion rate of a metal in liquid medium and hence the effectiveness of a specified substance as corrosion inhibitor. Sample zinc plates size $1 \mathrm{~cm} \times 4 \mathrm{~cm}$ were cut out from battery grade zinc sheet. After degreasing, cleaning and weighing, they were immersed separately in $\mathrm{NH}_{4} \mathrm{Cl}$ solution containing different addition agents. The immersion test was carried out at room temperature for 24 hours. The corrosion rate of the zinc plate can be evaluated, in principle, from its weight loss or from the volume of hydrogen evolved. Though the later method has the advantage of being able to give continuous results during the course of the experiment, its accuracy was found to be inferior to that of the former method at very low corrosion rates owing to the effects of gas solubility, temperature fluctuation etc., hence data of the former method were taken for evaluation.

\section{Polarization measurement}

The zinc electrode was made of battery grade zinc (99.9 wt\%). The cell electrolyte, principally $26 \% \mathrm{NH}_{4} \mathrm{Cl}$ solution with or without added inhibitor, was prepared with AR grade reagents and deareated by argon purging before measurement. A platinum foil was used as counter electrode and a saturated calomel electrode as reference, which is electrolytically connected to the zinc electrode. The measurement of polarization curves were performed with an EG\&G instrument, Electrochemical impedance analyzer, model 6310. After the potential of the immersed zinc electrode reached its steady value $\mathrm{E}_{\text {corr }}$ (changing no more than $2 \mathrm{mV} / \mathrm{min}$ ). The measurement was carried out by sweeping the potential within predetermined limits from negative to positive at a rate of $10 \mathrm{mV} / \mathrm{sec}$.

\section{Impedance measurements}

Electrochemical impedance measurements were performed using an EG\&G instrument, model 6310, PAR-398, frequency response analyzer. In this case the same three electrode assembly used as that in polarization measurement. Alternative current magnitude signal was of $5 \mathrm{mV}$ and the frequency range from $100 \mathrm{kHz}$ to $100 \mathrm{mHz}$. 


\section{Results and Discussion}

Figure 1-3 shows the linear sweep potentiostatic polarization curves of zinc in $26 \% \mathrm{NH}_{4} \mathrm{Cl}$ solutions containing different concentrations of substituted aliphatic sulphides. It is seen that, in the presence of EBS, DBS and AMS, the corrosion current of zinc, $i_{\text {corr }}$, decreased markedly while the corrosion potential, $\mathrm{E}_{\mathrm{corr}}$ shifted positively indicating that aliphatic sulphides are anodic type indicators.

Another feature to be noted from figures is that in solutions containing aliphatic sulphides, the slope of the anodic polarization curve gradually decreases at high anodic potentials, showing that the effect of aliphatic sulphides is declining. The immersion test also demonstrates that aliphatic sulphides added to $\mathrm{NH}_{4} \mathrm{Cl}$ solution can inhibit the corrosion of zinc, as is evident by comparison of the corrosion rates given in Table 1.

Table 1. Weight loss studies of the inhibitors in various concentrations for 24 hours

\begin{tabular}{ccccc}
\hline Inhibitor & $\begin{array}{c}\text { Inhibitor } \\
\text { Concentration } \\
\mathrm{mM}\end{array}$ & $\begin{array}{c}\text { Weight loss } \\
\mathrm{g}\end{array}$ & $\begin{array}{c}\text { Rate of Zn corrosion } \\
\mathrm{gcm}^{-2} \text { day }^{-1}\end{array}$ & $\begin{array}{c}\text { Efficiency } \\
\%\end{array}$ \\
\hline Blank & --- & 0.010 & 0.001250 & --- \\
Ethyl butyl & 0.5 & 0.004 & 0.000500 & 60 \\
sulphide & 1.0 & 0.005 & 0.000625 & 50 \\
& 1.5 & 0.006 & 0.000750 & 40 \\
Dibutyl & 0.5 & 0.005 & 0.000625 & 50 \\
sulphide & 1.0 & 0.003 & 0.000375 & 70 \\
& 1.5 & 0.002 & 0.000250 & 80 \\
Allyl methyl & 0.5 & 0.003 & 0.000375 & 70 \\
sulphide & 1.0 & 0.004 & 0.000500 & 60 \\
\hline
\end{tabular}

The inhibition of corrosion by organic molecules present may be caused either by a geometrical blocking effect or by chemical adsorption on active centers of the metal surface ${ }^{11}$. In the former case, the slopes of the cathodic and anodic polarization curves remain unchanged and so does the corrosion potential, $\mathrm{E}_{\text {corr }}$ of the metal. In the later case, both the slopes and $\mathrm{E}_{\text {corr }}$ change to some extent. From figure 1-3, it can be seen that substituted aliphatic sulphides belong to the later category. The values are given in Table 2.

The adsorption of organic molecules on a metal surface usually changes the value of double layer capacity, $C$, of the interface. For a plain plate capacitor, $C=\Sigma / 4 \pi \mathrm{d}$, where $\Sigma$ denotes the dielectric constant of the medium and ' $d$ ' the distance between the plates. Once chemical adsorption takes place, the water molecules within the interface are more or less replaced by larger sized organic molecules whose dielectric constant is much smaller than that of water. As a consequence, the double layer capacity decreases with increase in coverage by organic molecules that are the extent of adsorption.

The double layer capacity of an electrode interface can be obtained by A.C impedance measurement are given in Table 3. Figure 4-6 shows a typical Nyquist impedance spectrum of zinc electrode in $26 \% \mathrm{NH}_{4} \mathrm{Cl}$ solution. Bordering on a semicircle, the shape of this plot implies the electrode interface under study can conditionally be expressed by a charge transfer resistance, $R_{t}$, in parallel with the double layer capacitor, $C_{d l}$, the value of which is readily deduced by computer stimulation. In this manner we obtained the double layer capacity $\mathrm{C}_{\mathrm{dl}}$ of the zinc electrode at open circuit conditions, that is at $\mathrm{E}=\mathrm{E}_{\mathrm{corr}}$, as a function of concentration of aliphatic sulphides in the $\mathrm{NH}_{4} \mathrm{Cl}$ solution and time. The results are shown in 
Figures 4-6. On introducing a zinc electrode into $\mathrm{NH}_{4} \mathrm{Cl}$ solution, the electrode capacity $\mathrm{C}$ is seen to initially decrease gradually, after about one hour or more, it approaches a stable value. For pure $26 \% \mathrm{NH}_{4} \mathrm{Cl}$ solution without inhibitor, the stable value of $\mathrm{C}_{\mathrm{dl}}$ is about $30 \mu \mathrm{Fcm}^{-2}$ which is lower than the value of $40 \mu \mathrm{Fcm}^{-2}$ obtained by Baugh et al ${ }^{12}$ for zinc in wt $\% \mathrm{NH}_{4} \mathrm{Cl}$ solution probably because the zinc electrode used by Baugh et al., had been etched before measurement, making the true surface area of the electrode somewhat greater with substituted aliphatic sulphides added to the solution, $\mathrm{C}_{\mathrm{dl}}$ assumes smaller values until the concentration of substituted aliphatic sulphides reaches $0.5 \mathrm{mM}, 1.0 \mathrm{mM}$ and $1.5 \mathrm{mM}$, when it reaches a stable value of about $25 \mu \mathrm{Fcm}^{-2}$.

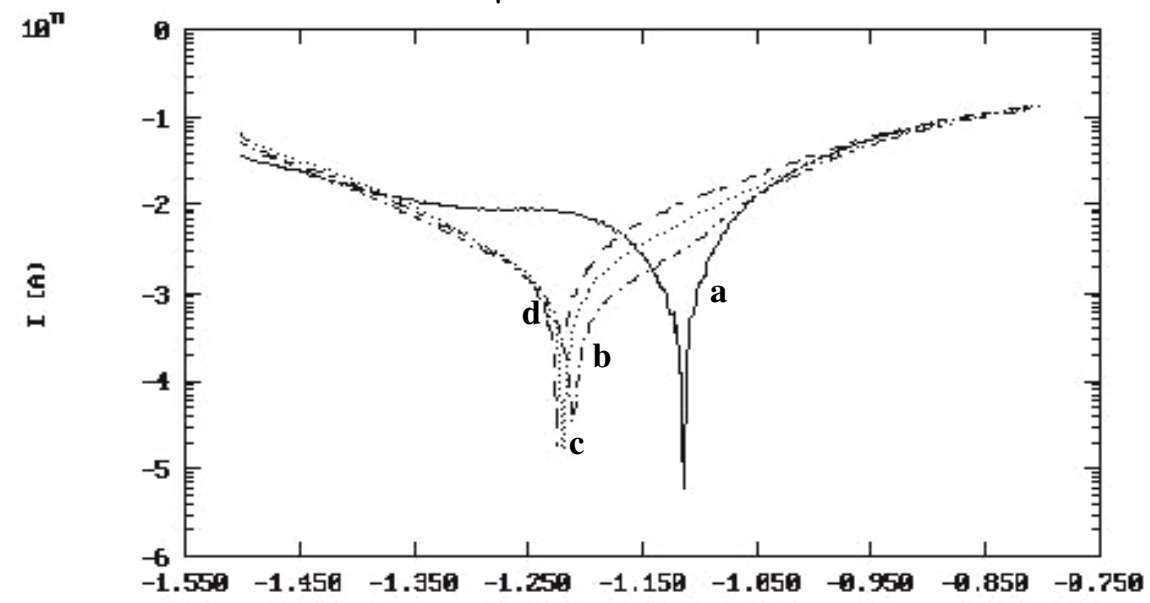

Figure 1. Potentiostatic polarization studies of the various concentrations of EBS (a) blank (b) $0.5 \mathrm{mM}$ (c) $1.0 \mathrm{mM}$ (d) $1.5 \mathrm{mM}$

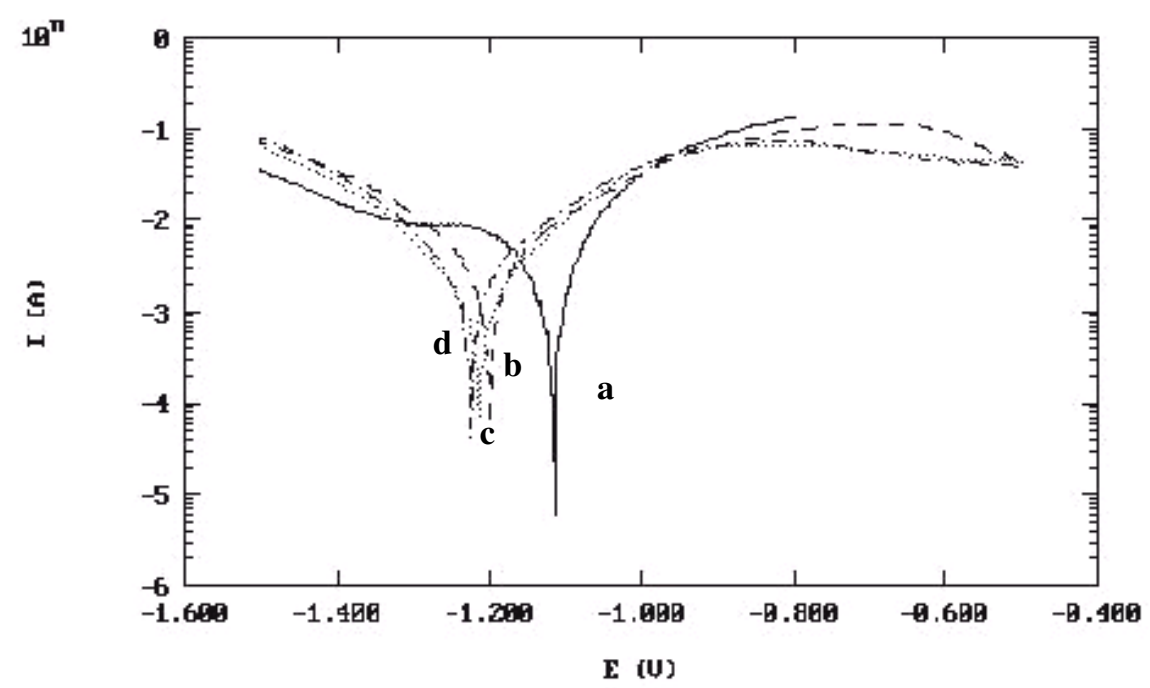

Figure 2. Potentiostatic polarization studies of the various concentrations of DBS (a) blank (b) $0.5 \mathrm{mM}$ (c) $1.0 \mathrm{mM}$ (d) $1.5 \mathrm{mM}$ 


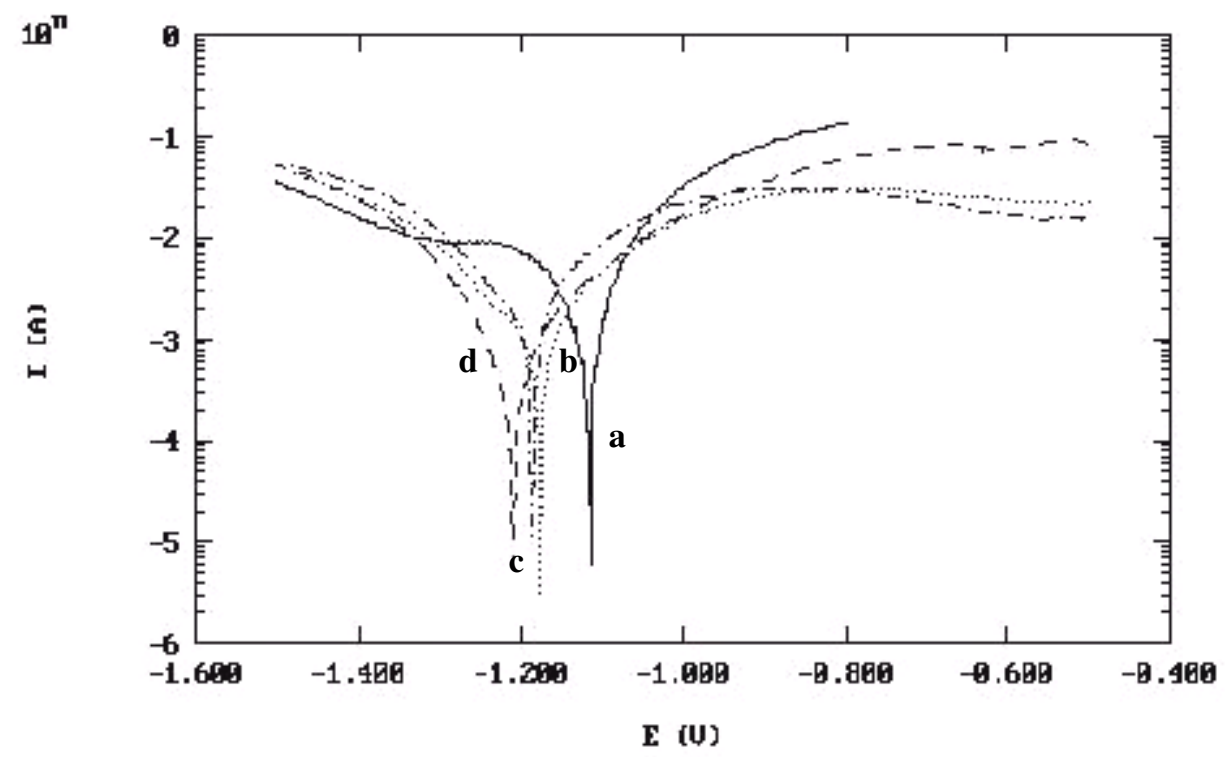

Figure 3. Potentiostatic polarization studies of the various concentrations of AMS (a) blank (b) $0.5 \mathrm{mM}$ (c) $1.0 \mathrm{mM}$ (d) $1.5 \mathrm{mM}$

Table 2. Polarization studies of the various inhibitors at different concentrations

\begin{tabular}{lccccc}
\hline Compound & $\begin{array}{c}\text { Inhibitor } \\
\text { Concentration } \\
(\mathrm{mM})\end{array}$ & $\begin{array}{c}\mathrm{E}_{\text {corr }} \\
(\mathrm{V})\end{array}$ & $\begin{array}{c}\mathrm{i}_{\text {corr }} \\
\left(\mathrm{x} \mathrm{10}^{-3}\right)\end{array}$ & $\mathrm{b}_{\mathrm{a}}$ & $\mathrm{b}_{\mathrm{c}}$ \\
\hline Blank & --- & -1.115 & 3.6307 & 0.1103 & 0.2310 \\
Ethyl butyl & 0.5 & -1.226 & 2.0431 & 0.1586 & 0.1828 \\
$\quad$ sulphide & 1.0 & -1.221 & 0.7943 & 0.4615 & 0.3744 \\
& 1.5 & -1.210 & 0.7279 & 0.1241 & 0.1000 \\
Dibutyl & 0.5 & -1.198 & 0.7279 & 0.3077 & 0.3026 \\
sulphide & 1.0 & -1.210 & 1.3768 & 0.1282 & 0.1282 \\
& 1.5 & -1.224 & 3.0654 & 0.1949 & 0.1436 \\
Allyl & 0.5 & -1.209 & 1.7433 & 0.2205 & 0.1538 \\
methyl & 1.0 & -1.178 & 1.8478 & 0.1590 & 0.1590 \\
sulphide & 1.5 & -1.186 & 1.4874 & 0.1149 & 0.1128 \\
\hline
\end{tabular}

Thus, the above-mentioned substituted aliphatic sulphides are an anodic type inhibitor capable of inhibiting the anodic reaction of zinc corrosion when adsorbed on active zinc centers. Let $\mathrm{f}=\mathrm{I}$ '/I where $\mathrm{f}$, I' and I denote the function of adsorption energy, anodic current densities of a zinc electrode at the same anodic shift from rest potential in $\mathrm{NH}_{4} \mathrm{Cl}$ solutions with and without aliphatic sulphides respectively. The variations of $f$ with anodic potential shift were determined from zinc anodic polarization curves. 
Table 3. Impedance studies of the various inhibitors at different concentrations

\begin{tabular}{lcccccc}
\hline Compound & $\begin{array}{c}\text { Inhibitor } \\
\text { concentration } \\
\mathrm{mM}\end{array}$ & $\begin{array}{c}R_{s} \\
\mathrm{ohm}\end{array}$ & $\begin{array}{c}\mathrm{R}_{\mathrm{s}}+\mathrm{R}_{\mathrm{t}} \\
\mathrm{ohm}\end{array}$ & $\begin{array}{c}\mathrm{R}_{\mathrm{t}} \\
\mathrm{ohm}\end{array}$ & $\mathrm{f}_{\max }$ & $\begin{array}{c}\mathrm{Z}=1 / \omega \mathrm{Rt} \\
\times 10^{-6}\end{array}$ \\
\hline $\begin{array}{l}\text { Blank } \\
\text { Ethylbutyl } \\
\text { sulphide }\end{array}$ & --- & 111.3 & 214.4 & 103.1 & 631 & 2.44640 \\
& 0.5 & 7.167 & 199.1 & 191.93 & 2512 & 0.33011 \\
& 1.0 & 2.244 & 287.2 & 284.96 & 2512 & 0.22234 \\
$\begin{array}{l}\text { Dibutyl } \\
\text { sulphide }\end{array}$ & 1.5 & 2.806 & 349.3 & 346.49 & 2512 & 0.18276 \\
& 0.5 & 12.640 & 320.5 & 307.86 & 3981 & 0.12986 \\
& 1.0 & 14.470 & 326.9 & 312.43 & 1585 & 0.32139 \\
Allylmethy & 1.5 & 92.9 & 10520 & 10427.1 & 9.710 & 0.15719 \\
1 sulphide & 0.5 & 5.447 & 295.9 & 290.45 & 631 & 0.86840 \\
& 1.0 & 4.074 & 302.8 & 298.73 & 631 & 0.84433 \\
& 1.5 & 6.115 & 56.06 & 49.95 & 3981 & 0.80037 \\
\hline
\end{tabular}

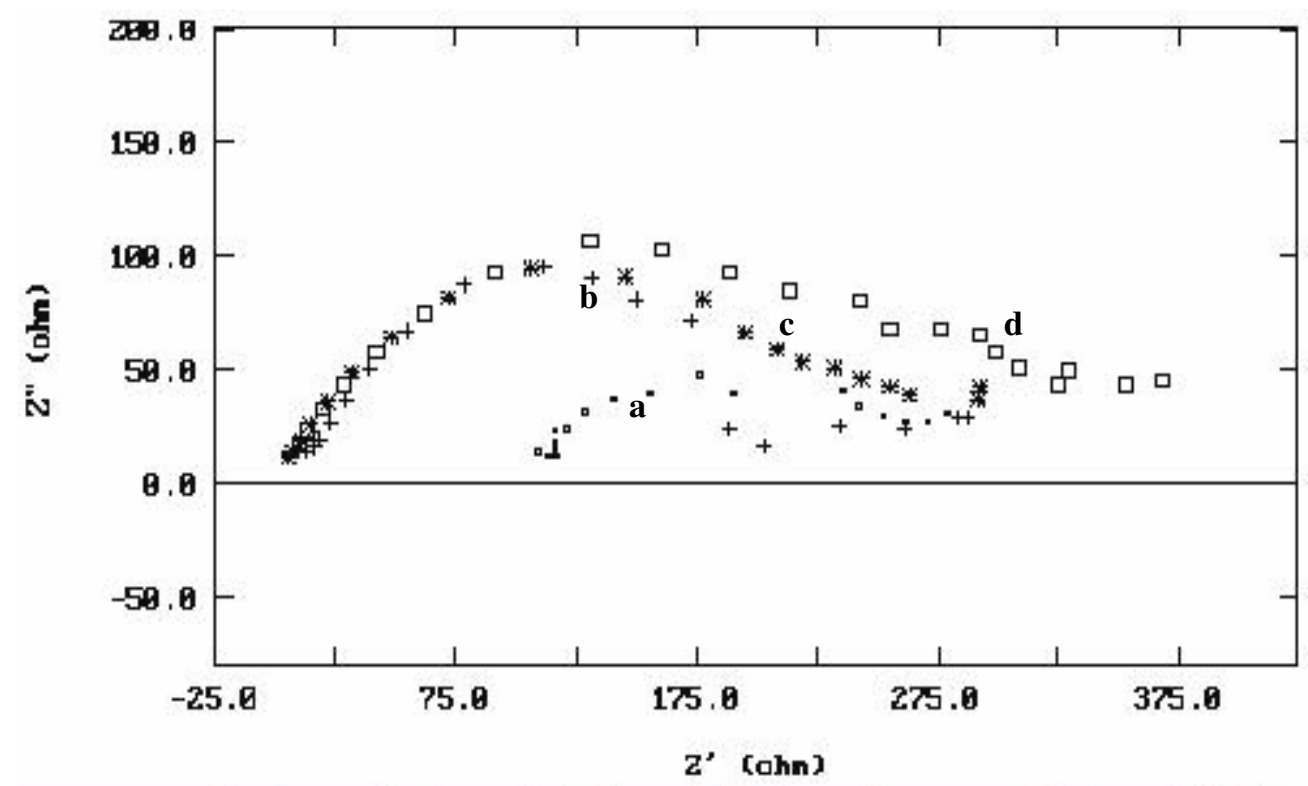

Figure 4. Impedance measurement for various concentrations of EBS

(a) Blank (b) $0.5 \mathrm{mM}$ (c) $1.0 \mathrm{mM}$ (d) $1.5 \mathrm{mM}$ 


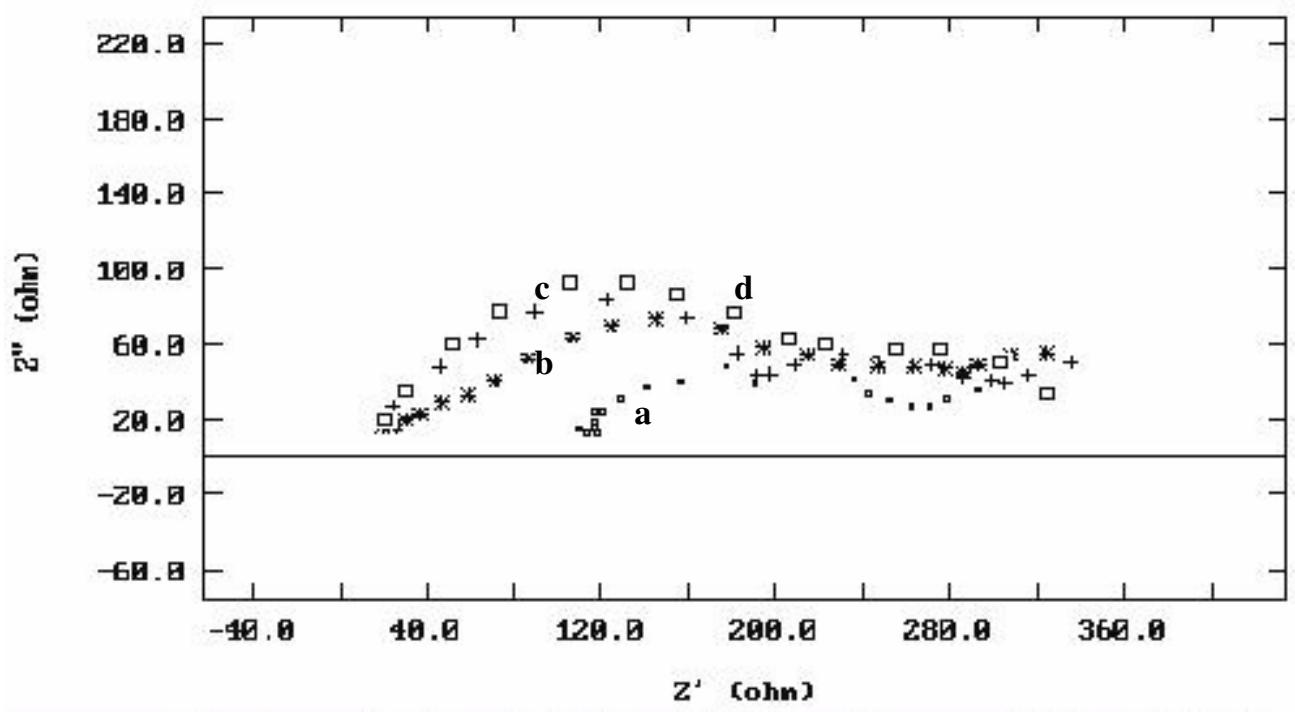

Figure 5. Impedance measurement for various concentrations of DBS (a) Blank (b) $0.5 \mathrm{mM}$ (c) $1.0 \mathrm{mM}$ (d) $1.5 \mathrm{mM}$

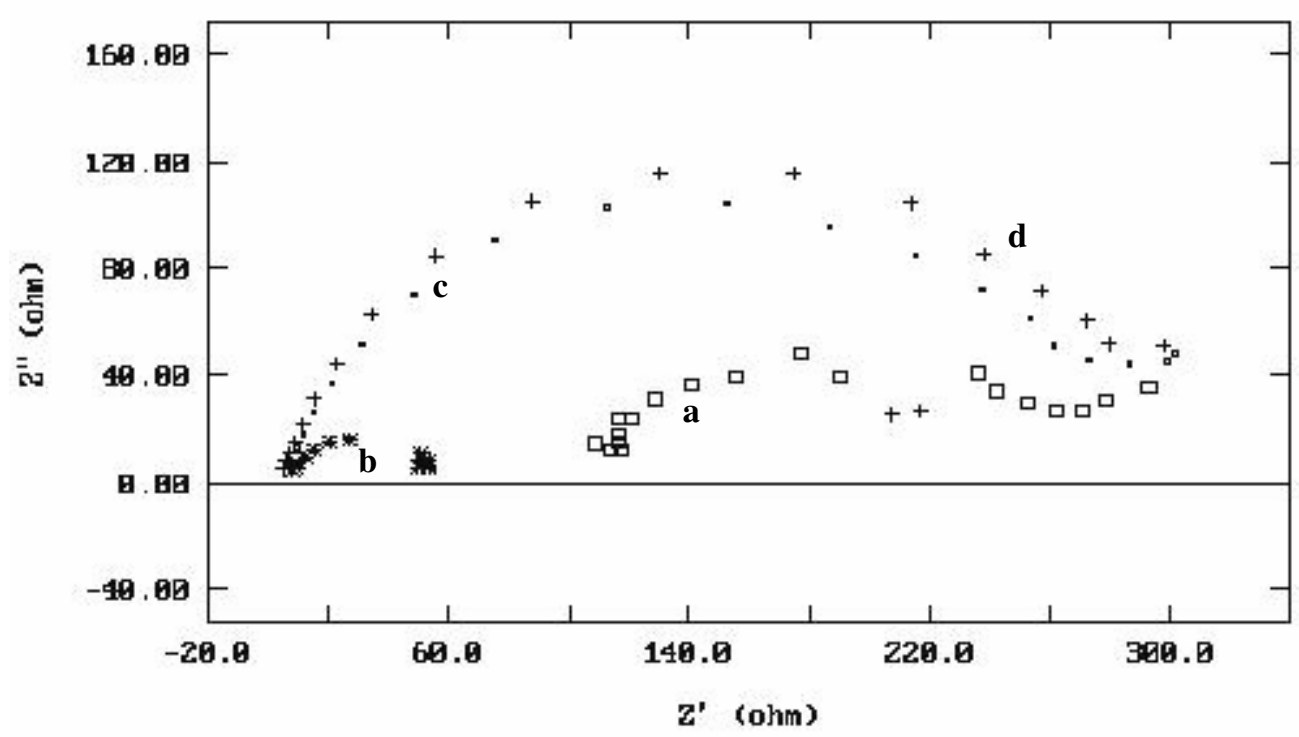

Figure 6. Impedance measurement for various concentrations of AMS (a) Blank (b) $0.5 \mathrm{mM}$ (c) $1.0 \mathrm{mM}$ (d) $1.5 \mathrm{mM}$ 


\section{Conclusion}

The substituted aliphatic sulphides like EBS, DBS and AMS manifests itself as an anodic type inhibitor. The inhibition of zinc corrosion in $26 \% \mathrm{NH}_{4} \mathrm{Cl}$ solution results from the adsorption of the organic molecule on the active centers of zinc surface. The effect of the inhibitors on anodic dissolution of zinc diminishes with positive shift of the zinc electrode potential. This feature makes aliphatic sulphides like EBS, DBS and AMS, which are possible substitute for mercury salt as the corrosion inhibitor in Zinc - Manganese dry batteries.

\section{References}

1. Rudresh H B and Mayanna S M, J.Electrochem.Soc., 1982, 31-4, 109.

2. Mansour H, Noubi G A and Abu-Elwafa M H, J.Electrochem.Soc., 1985, 34, 237.

3. Rudresh H B and Mayanna S M, British Corrosion J., 1977, 12, 54.

4. Yu.R, Ipatov and Batrotov V V, Electrokhimiya, 1980, 16, 624

5. Li,L.J, Zhang S T, Li D, Yuang Y and Huang Z, Electrochem. Soc., $197^{\text {th }}$ Spring meeting, Extended Abstracts, Toronto, Ontario, Canada, 2000, 1, 134

6. Gonzalez S, Gil MA, Hernandez J O, Fox V and Soutto R M, Protective Organic Coatings, 2001, (1-3), 41,167

7. Hoar T P and Holliday R D, J. Appl. Chem., 1953, 3, 502

8. Hackerman N and Trans N Y Acad. Sci., 1954, 17, 7

9. Gad Allah A G, Hefny M M Salih S A and El-Basiouny M S, Corrosion, 1989, 45, 574.

10. Maja M, Penazzi N, Fernia G and Sandera G, Electrochim Acta., 1998, 38, 1453.

11. Cao Ch, Corrosion Control (Proceedings $7^{\text {th }}$ APCCC), 1991, 901.

12. Baugh L M, Tye F L and White N C, J. Appl. Electrochem, 1983, 13, 623 


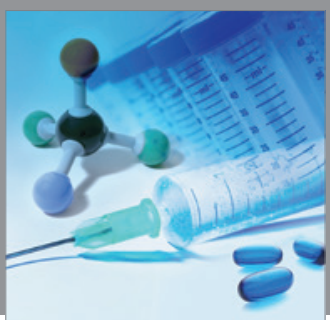

International Journal of

Medicinal Chemistry

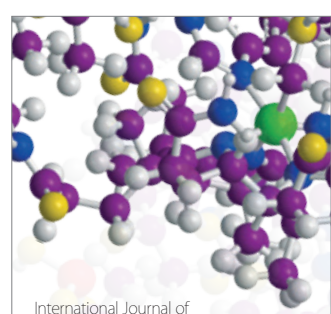

Carbohydrate Chemistry

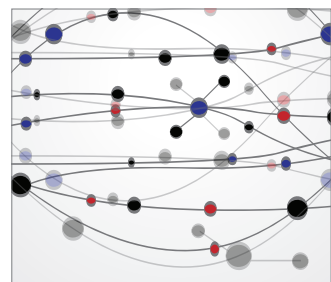

The Scientific World Journal
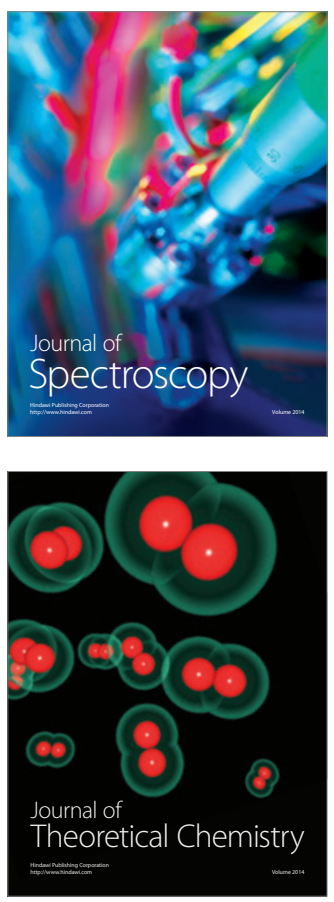
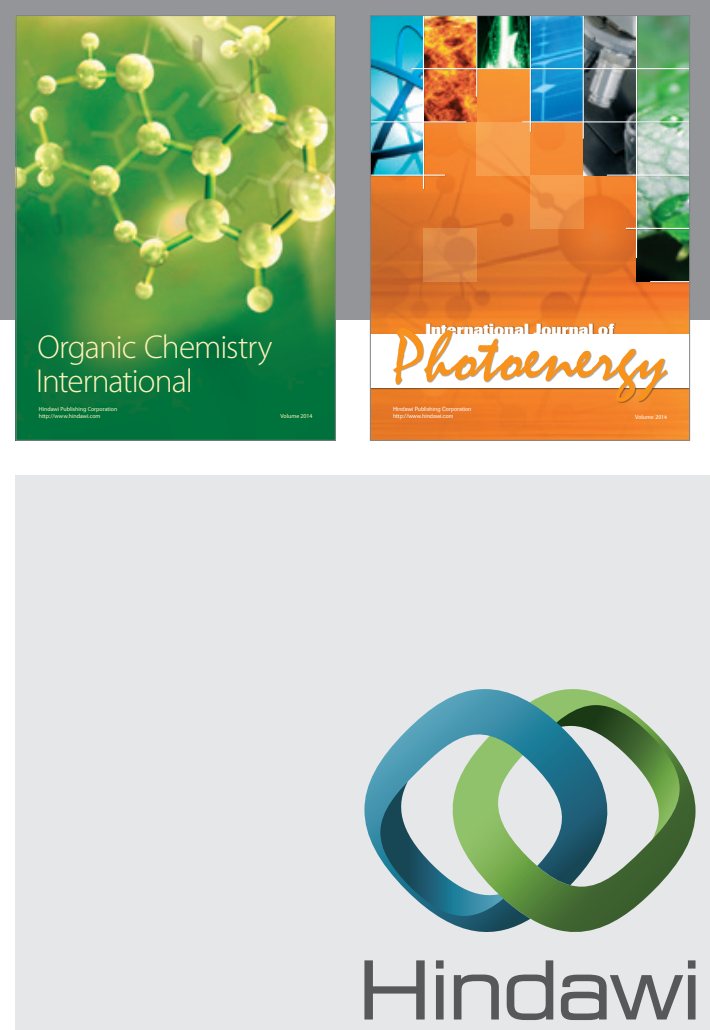

Submit your manuscripts at

http://www.hindawi.com
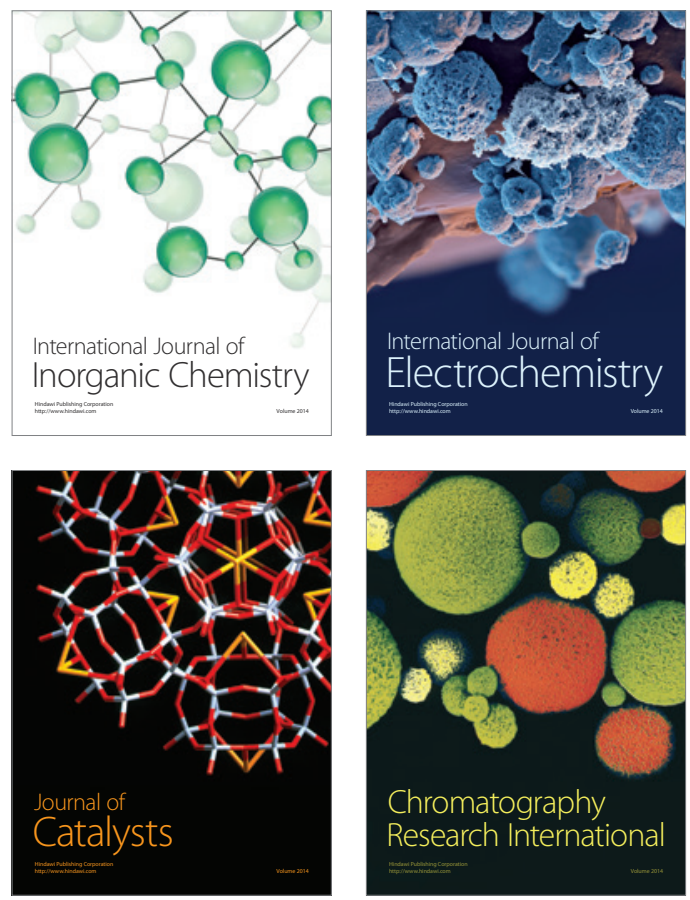
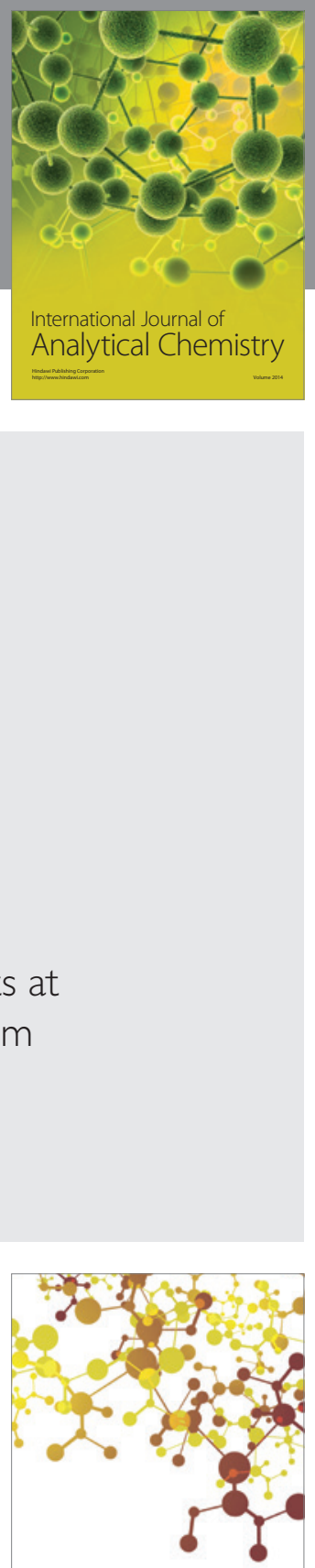

Journal of

Applied Chemistry
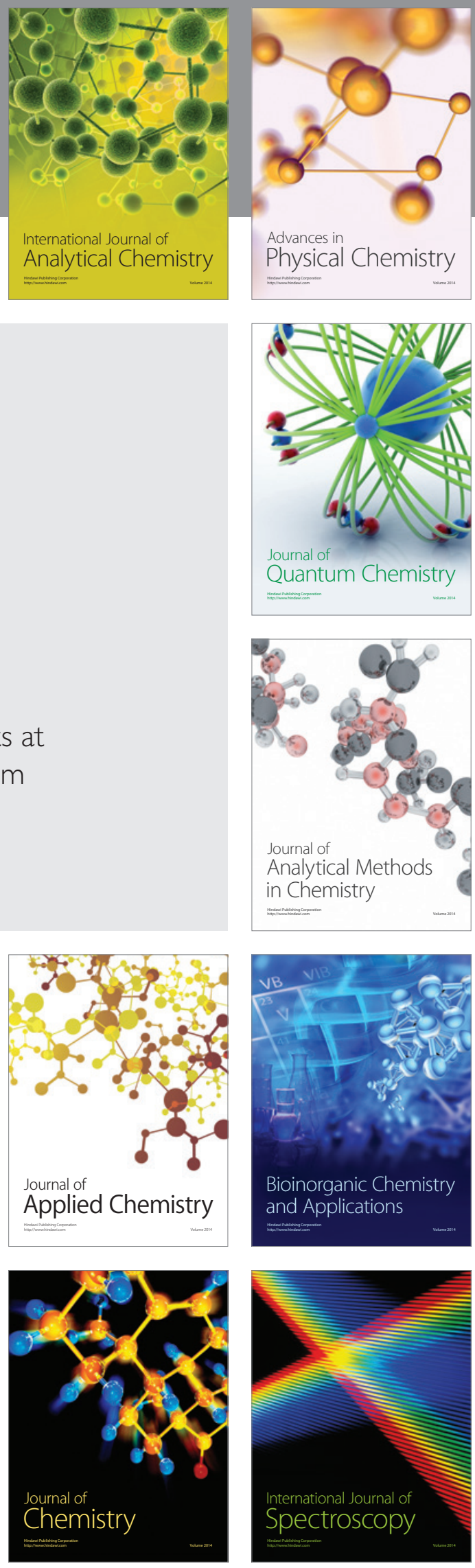